\title{
El incendio de la Cárcel de San Miguel, su veredicto absolutorio y las obligaciones internacionales de protección de los derechos humanos involucradas The fire of San Miguel prison: It's veredict of acquittal and the international obligation to protect the involved human rights
}

\author{
Karinna Fernández Neira \\ University College London, Reino Unido
}

Abogada chilena de la Universidad de Valparaíso, Magíster en Derecho de la Universidad de Chile. Actualmente candidata a LLM en la Universidad de Essex. Con experiencia en litigios nacionales e internacionales, ha asesorado a diversas organizaciones europeas en legislación regional, como la FIDH, la OMCT, y REDRESS. A partir de enero de 2014, es investigadora asociada del Instituto de las Américas, de la University College London.

k.neira@ucl.ac.uk

\section{Nancy Carmina García Fregoso}

University of Essex, Reino Unido

Abogada mexicana de la Facultad Libre de Derecho de Monterrey, cuenta con estudios en derecho en la Universidad de Regensburg (Alemania) y es licenciada en Filosofía de la Universidad de Arizona. Actualmente candidata a LLM en la Universidad de Essex. Trabajó en la Coordinación de Derechos Humanos de la Suprema Corte de Justicia de México, y se desempeñó en el Consejo de Derechos Humanos de la Organización de las Naciones Unidas, y en la Embajada de México en Alemania.

nancygarciafregoso@gmail.com

\section{RESUMEN}

Este artículo presenta argumentos sobre la responsabilidad internacional del Estado chileno por el incendio ocurrido en la Cárcel San Miguel en el que murieron 81 internos y otros 13 resultaron gravemente lesionados. Para ello se invoca la normativa internacional aplicable a este caso, relativa al trato de las personas privadas de libertad y las obligaciones generales que pesan sobre el Estado en materia de derechos humanos. También se menciona en términos generales, la realidad carcelaria chilena y del penal de San Miguel. Finalmente, se sostiene que las omisiones en el deber de cuidado de los agentes del Estado y de la obligación de sancionar por parte del Poder Judicial, constituyen graves violaciones a los derechos humanos de las personas privadas de libertad y de sus familiares.

Palabras clave: Incendio de la Cárcel San Miguel hacinamiento - condiciones carcelarias - deber de cuidado - obligaciones internacionales - personas privadas de la libertad.

\begin{abstract}
This article presents arguments about the international responsibility of the Chilean State derived from the fire occurred in the San Miguel Prison, in which 81 internees died and other 13 result severely injured. Therefore the authors refer to the international law applicable in this case in relation to the persons deprived of liberty and the general obligations of the State in matter of human rights. Additionally, the conditions of imprisonment in Chile and specifically those of the San Miguel Prison are addressed. Finally, it is argued that the omissions in the duty of care of the agents of the State and the obligation of the Judicial System to sanction constitute serious violations of human rights of the persons deprived of liberty and their families.

Key words: San Miguel Prison fire - overcrowding - conditions of imprisonment - duty of care - international obligations - persons deprived of liberty.
\end{abstract}




\section{Introducción}

En junio de 2014 el Sexto Tribunal de Juicio Oral en lo Penal (en adelante, TJOP) ${ }^{1}$ dictó sentencia en el proceso penal originado por el incendio ocurrido la madrugada del 8 de diciembre de 2010 en el Centro de Detención Preventiva de San Miguel, donde murieron 81 internos y otros 13 resultaron lesionados. El veredicto absolvió a los ocho acusados de los cargos imputados, como coautores de los cuasidelitos de homicidios y lesiones reiteradas ${ }^{2}$.

La argumentación penal seguida por el tribunal fue objeto de sendos recursos de nulidad por parte del Ministerio Público y los querellantes, que fueron desestimados por la Corte de Apelaciones de San Miguel $^{3}$. Sin embargo, en lugar de enfocarnos en las falencias de orden penal del veredicto absolutorio, el objeto de este comentario es centrarnos críticamente en la ausencia de consideraciones relativas a las obligaciones internacionales que pesan sobre el Estado chileno, derivadas del derecho internacional de los derechos humanos, haciendo énfasis en las diversas instituciones del derecho internacional aplicables al caso y que fueron desconocidas por el órgano juzgador.

En primer lugar, nos referiremos brevemente a los principales aspectos del veredicto absolutorio y al contexto en que se produjo el incendio, para luego hacer una reseña de las normas de derecho internacional involucradas. Finalmente, daremos cuenta de las obligaciones generales que involucran al Estado de Chile, especialmente en casos criminales que constituyen graves violaciones a los derechos humanos, para concluir que tanto la falta de sanción de los responsables, como la ausencia de consideración a las normas internacionales aplicables durante el proceso penal genera la correspondiente responsabilidad internacional del Estado de Chile ${ }^{4}$.

\section{Síntesis del veredicto en análisis: principales aspectos debatidos}

A juicio del órgano persecutor la responsabilidad cuasidelictual de los acusados se derivó de la posición de garante que ostentan los funcionarios de Gendarmería de Chile ${ }^{5}$ y del incumplimiento de sus deberes de cuidado por omisión impropia ${ }^{6}$.

1 Sexto Tribunal de Juicio Oral en lo Penal. Sentencia de 13 de Junio de 2014. Causa RUC N 1.001.141.178-4.

2 Ilícito previsto y sancionado en los artículos 492 y 490 en relación con los artículos 391 № 2, 397 № 2, y 399 del Código Penal, la Ley Orgánica de Gendarmería de Chile ( $\left.N^{\circ} 2859\right)$, en sus artículos $1^{\circ}, 3^{\circ}$ letra e) 1 y artículo $15^{\circ}$; los artículos $1^{\circ}, 4^{\circ}, 6^{\circ}$ inciso final, $10^{\circ}$ letra d y 25 del Reglamento de Establecimientos Penitenciarios Decreto Supremo 518 ; y lo dispuesto la resolución 2854 de Organización Administrativa de los Establecimientos Penitenciarios y el Protocolo de Acción Contra Incendio.

3 Ilustrísima Corte de Apelaciones de San Miguel. Sentencia de 28 de agosto de 2014. Rol No 979-2014.

4 Por permanecer pendiente la demanda civil entablada por las víctimas bajo el Rol № C-8082-2011 ante el $7^{\circ}$ Juzgado Civil de Santiago, no abordaremos las obligaciones internacionales relativas a reparación y garantías de no repetición. Aunque conviene observar que las obligaciones vinculadas a los artículos 8 y $25 \mathrm{CADH}$, en relación con el artículo 1 del mismo instrumento, no se agotan con la vía civil, existiendo además el deber de sancionar penalmente a los responsables de violaciones a derechos humanos.

5 Gendarmería de Chile (en adelante, Gendarmería) es un Servicio Público dependiente del Ministerio de Justicia, que tiene por finalidad atender, vigilar y rehabilitar a las personas que por resolución de autoridades competentes, fueren detenidas o privadas de libertad y cumplir las demás funciones que le señale la ley (Art. $1^{\circ}$, Ley Orgánica Gendarmería de Chile). En particular el artículo $6^{\circ}$ de Reglamento de Establecimientos Penitenciarios, establece que "La Administración Penitenciaria velará por la vida, integridad y salud de los internos y permitirá el ejercicio de los derechos compatibles con su situación procesal".

6 A modo de ejemplo jurisprudencial de condena a título de comisión por omisión dolosa de homicidio, Corte Suprema. Caso contra Castro Muñoz. Sentencia de 4 de agosto de 1998. Véase en doctrina, por ejemplo, BUSTOS, Juan. El delito culposo, Santiago, Editorial Jurídica de Chile, 1995; IZQUIERDO, Cristóbal. Comisión por Omisión. Algunas Consideraciones sobre la Injerencia como Fuente de la Posición de Garante. Revista Chilena de Derecho, (33): pp. 329343, 2006. 
Los deberes generales del personal de Gendarmería implican la obligación de salvaguardar los derechos de las personas privadas de libertad que se encuentran bajo su custodia, y que conllevan, entre otras, las siguientes obligaciones específicas previstas en leyes ${ }^{7}$ y reglamentos ${ }^{8}$ : estar atentos y vigilantes durante el desempeño de sus funciones, efectuar rondas "permanentes y continuas", otorgar seguridad y resguardo a la población penal, controlar la tenencia y uso de material combustible por parte de los internos, crear y actualizar el plan de contingencia contra incendios y realizar simulacros.

A pesar de que la posición de garante de los acusados fue reconocida por el tribunal ${ }^{9}$, el veredicto negó que la inobservancia de las obligaciones contenidas en diversas resoluciones, protocolos y minutas, constituyeran "infracciones reglamentarias" en los términos exigidos por el artículo 492 del Código Penal ${ }^{10}$, por no tratarse de "reglamentos" ${ }^{11}$. Esta interpretación "restrictiva" elegida por el Tribunal se contrapone a lo indicado previamente por el Tribunal Constitucional chileno que ha afirmado que el concepto de "reglamento" utilizado por la norma debe ser entendido en sentido amplio, toda vez que circunscribe el ámbito en que la acción imprudente a cuestiones que se encuentren de alguna forma regladas ${ }^{12}$. Afirmación que resulta armónica con la doctrina penal, que sostiene que la expresión reglamento tiene un papel limitador de la conducta exigida en los delitos culposos y no esencial al injusto, por tanto no debe realizarse una interpretación restrictiva, ya que no afecta el principio de legalidad ${ }^{13}$. Se debe entender, entonces, por reglamento "todas aquellas normas jurídicas dadas por la autoridad para regular una determinada actividad"14, tratándose de normas de regulación o reglas técnicas que contienen "Ilamadas de atención en relación a precauciones que ha de tomar el sujeto"15, es decir, disposiciones generales que determinan un mínimo de medidas de precaución que la persona que se desempeña en un ámbito de relación reglamentada debe conocer y respetar.

7 Decreto Ley No 2.859. CHILE. Ley Orgánica de Gendarmería de Chile, 12 de Septiembre de 1979. Artículos $1^{\circ}$ y $3^{\circ}$ Letra e) número 1 y 15.

8 Decreto Supremo N N 518. CHILE. Reglamento de Establecimientos Penitenciarios, Ministerio de Justicia, de 22 de mayo de 1998; Resolución 2854 de Organización Administrativa de los Establecimientos Penitenciarios; Protocolo de Acción Contra Incendio, resolución № 6526, de 28 de diciembre de 2009; Providencias emanadas del Alcaide del centro de detención preventiva de San Miguel; Plan Maestro para enfrentar Eventos Críticos.

9 Sexto TJOP. op. cit., considerando 160 “En el caso particular, si bien el Tribunal no tiene ninguna duda de que el acusado tiene una posición de garante, y que se produjo un resultado, entiende que no estaba en posibilidad real de evitar este resultado".

10 Artículo 492, inciso primero: “Las penas del artículo 490 se impondrán también respectivamente al que, con infracción de los reglamentos y por mera imprudencia o negligencia, ejecutare un hecho o incurriere en una omisión que, a mediar malicia, constituiría un crimen o un simple delito contra las personas".

11 Sexto TJOP. op. cit., considerando $271^{\prime \prime}[. .$.$] el Tribunal entiende que si lo que se pretende por parte de los acusadores$ es sancionar conductas que habrían sido omitidas por los acusados, al menos estas acciones que se pretenden imponer deben estar contenidas en documentos que tengan existencia legal, es decir, que hayan sido dictados por autoridad competente, en uso de sus facultades reglamentarias, y que hayan sido publicados [...]", "El Tribunal a la hora de analizar formalmente los documentos (invocados por el acusador), se encuentra en la necesidad de interpretar su naturaleza jurídica en forma restrictiva".

12 Tribunal Constitucional. Sentencia de 14 de junio de 2012, Rol No 2154-2011-INA, considerando 49.

13 Véase: BUSTOS, Juan, op. cit., p. 53; POLITOFF, Sergio, MATUS, Jean Pierre y RAMÍREZ, María Cecilia. Lecciones de Derecho Penal Chileno: Parte General. $2^{a}$ ed. Santiago, Editorial Jurídica de Chile, 2003, pp. 291-292; MARTíNEZ, Marco. La graduación del deber de cuidado en el delito culposo por actos de mala praxis médica: un análisis dogmático, jurisprudencial y económico. Política Criminal (12): 214-251, 211, p. 214.

14 BUSTOS, Juan, op. cit., p. 47.

15 Ibídem, p. 53. 
Así, si bien tales normas de regulación no constituyen parte del tipo penal, el juez al enjuiciar el comportamiento desarrollado por el acusado en su ámbito profesional o técnico, tiene "el deber de considerar el cuidado o llamado de atención" ${ }^{16}$ que se contempla en dichas disposiciones. Sin embargo, el Tribunal tampoco analizó el incumplimiento de las obligaciones contenidas en aquellos escasos cuerpos normativos que a su juicio, sí poseían el carácter de reglamentos ${ }^{17}$. En particular, no hace ninguna mención al artículo 4 del Reglamento de Establecimientos Penitenciarios que se refiere precisamente a la obligación del personal de Gendarmería de observar en su accionar lo dispuesto en "los tratados internacionales ratificados por Chile".

Adicionalmente, el Tribunal sostuvo que no existió relación causal entre las omisiones imputadas y el resultado lesivo, utilizando como parámetro el que "con la realización de las conductas que se alegan como omitidas en las acusaciones, se hubiese evitado el resultado producido en una proporción lindante con la certeza"18. Estándar diverso al utilizado por la Corte Suprema chilena, que ha afirmado que la relación causal debe observarse en un sentido potencial. Es decir, se debe evaluar si con un comportamiento adecuado por parte de los acusados el resultado lesivo podría ser "razonablemente evitable"19, o bien, si el actuar negligente incrementó el riesgo del resultado lesivo, debiendo considerar "la realidad del exceso de riesgo creado por el autor del hecho imprudente" ${ }^{20}$. Así, el Tribunal afirmó:

\footnotetext{
"finalmente, es dable consignar que el artículo 492 del Código Penal exige para su configuración no solo tener por acreditada la infracción de reglamentos (la que en el caso sub lite no aconteció) sino que también el hecho que el agente haya actuado con negligencia (situación que tampoco fue probada), todo ello en concomitancia con la relación de causa a efecto que debe existir entre la infracción reglamentaria y el resultado dañoso"21.
}

Los querellantes argumentaron en sus recursos de nulidad que el Tribunal vulneró los principios rectores de valoración de las pruebas al no ponderar toda la evidencia rendida durante el juicio, dando origen a un veredicto plagado de interpretaciones e impresiones sesgadas, que solo se refirió en términos generales a la realidad carcelaria del penal de San Miguel, sin analizar el marco normativo que fija las conductas obligatorias para el personal de Gendarmería, especialmente las relacionadas con el control del riesgo. Con base en ese análisis, el tribunal concluyó que los acusados actuaron como les era exigible en el precario contexto del penal. Por ello, los querellantes y el Ministerio Público fundaron sus recursos bajo las causales contenidas en las letras b) y e) del artículo 374 en relación con los artículos 342 letra c) y 297 del Código procesal penal, recursos que fueron rechazados por el tribunal de alzada $^{22}$, confirmándose las absoluciones.

16 Ibídem, p. 47.

17 Sexto TJOP. op. cit., considerando 271 “(...) Del examen de la normativa invocada por los acusadores, solo cumplen con dichas exigencias la Resolución № 2854 de Organización Administrativa de Establecimientos Penitenciarios, la Ley Orgánica de Gendarmería de Chile, y el Reglamento de Establecimientos Penitenciarios".

18 Sexto TJOP. op. cit., considerando 160.

19 Corte Suprema. Caso en contra de Juan Selim Abuhadba en relación a la muerte del menor Exequiel Aravena. Sentencia de 28 de enero de 1999, considerando 2.

20 Corte Suprema, Sentencia de 12 de noviembre de 2013, Rol № 2870-2002, considerando 3. Véase en doctrina, por ejemplo, BUSTOS, Juan. op. cit., p. 53-54; IZQUIERDO, Cristóbal. op. cit., p. 336; ETCHEBERRY, Alfredo. Derecho

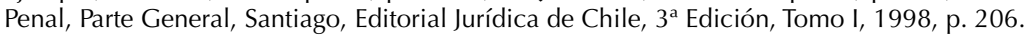

21 Sexto TJOP. op. cit., considerando 278.

22 Ilustrísima Corte de Apelaciones de San Miguel. Sentencia de 28 de agosto de 2014. Rol № 979-2014. 


\section{Condiciones carcelarias}

La muerte de los internos evidenció "las indignas condiciones carcelarias en que viven cerca de 54.000 personas en Chile, así como la ausencia de una política pública" ${ }^{23}$ destinada a corregir tales condiciones. El Relator Especial sobre Derechos de las Personas Privadas de Libertad de la Comisión Interamericana de Derechos Humanos $(\mathrm{CIDH})$ ha reportado que en los centros de detención chilenos existe "un alto nivel de hacinamiento pocas veces visto en la región, condiciones de insalubridad extrema que incluyen servicios precarios o deficientes de agua potable, alimentación, higiene y salud, así como pésimas condiciones de infraestructura" ${ }^{24}$. Ubicándose en el segundo lugar con el número más alto de internos muertos de la región ${ }^{25}$.

En junio de 2009, la Fiscal Judicial de la Corte Suprema chilena describió ante el Senado las condiciones de hacinamiento deplorables de las cárceles, señalando que los internos permanecían encerrados en sus celdas por aproximadamente quince horas diarias sin servicios sanitarios, sin ventilación, ni luz ${ }^{26}$. El mismo año, el Consejo para la Reforma Penitenciaria informó que entre 1998 y 2009 de 60.990 internos se aumentó a $106.877^{27}$

Al momento del siniestro, el CDP tenía una población de 1.956 internos, con un 197\% de sobrepoblación ${ }^{28}$. El lugar contaba con pésimas condiciones de ventilación, el servicio de agua era deficiente y la alimentación escasa, por ello los internos debían prepararse sus propias comidas en los reducidos espacios, lo que explica que contaran con balones de gas. Existía además una mala clasificación de los internos por delito y eran recluidos al interior de las torres, sin presencia interna de personal de vigilancia. Los espacios eran recintos con una sola entrada y salida que estaba determinada por una reja que tenía dos candados, no había cámaras de vigilancia, detectores de humo, regadores de agua, ni salidas de emergencia ${ }^{29}$.

\section{El incendio}

La madrugada del 8 de diciembre de 2010, un grupo de internos de la torre cinco, cuarto piso, ala sur, comenzaron a ingerir alcohol, generando una riña. Los bandos estaban subdivididos en "la pieza chica" y "la pieza grande", espacios particularmente precarios, desprovistos de iluminación y ventilación, donde habitaban 146 personas, esto es un $300 \%$ de hacinamiento ${ }^{30}$. Durante la riña se utilizaron elementos punzocortantes de distintas dimensiones y un balón de gas, que fue acondicionado como lanzallamas.

\footnotetext{
23 Instituto Nacional de Derechos Humanos (INDH). Informe Anual 2011: Situación de los Derechos Humanos en Chile. Santiago, INDH, 2011, p. 7.

24 CIDH. Comunicado de Prensa. No. 39/08. Disponible [en línea] <http://www.cidh.org/Comunicados/Spanish/2008/39.08sp. htm> [consulta: 26 de julio de 2014]

$25 \mathrm{CIDH}$. Informe sobre los derechos humanos de las personas privadas de libertad en las Américas. Washington, $\mathrm{CIDH}$, 2011, p. 6.

26 Informe elaborado por la Fiscalía Judicial de la Corte Suprema a propósito de la invitación de la Comisión de Constitución, Legislación, Justicia y Reglamento del Senado de la República, a la sesión del día 1 de junio de 2009.

27 Consejo para la Reforma Penitenciaria. Recomendaciones para una nueva política penitenciaria. 2010, p. 1. Disponible [en línea] <http://www.cesc.uchile.cl/Informe_CRPenitenciaria.pdf> [consulta: 26 de julio de 2014]

28 INDH. Informe Anual 2011... op. cit., p. 21.

29 Detalles sobre condiciones carcelarias del penal de San Miguel, En: Sexto TJOP. op. cit., considerandos 45-54.

30 Ibídem, considerando 19.
} 
Los guardias del recinto no pudieron prevenir estos acontecimientos, ya que no efectuaron las rondas al interior de las torres, tal como lo exige su reglamento ${ }^{31}$, permaneciendo en el perímetro externo del recinto. Posteriormente, tampoco actuaron frente a los gritos ni al desplazamiento de estoques de más de dos metros por los muros externos de la torre.

En este contexto, el incendio se originó por la utilización del balón de gas acondicionado como lanzallamas cuyas Ilamas se propagaron alrededor de las 5:00 horas. Los bomberos fueron alertados del siniestro a las 05:47 horas, por la llamada efectuada por un interno. El peritaje del Cuerpo de Bomberos estimó que a las 5:45 "las Ilamas consumieron por completo el ala sur del penal, dejando atrapados a los internos y comenzando a matar por asfixia a los reos del ala norte. Recién a esta hora las cámaras de seguridad registran movimiento por parte de los funcionarios de Gendarmería"32.

Los funcionarios no utilizaron los escasos mecanismos ni protocolos de emergencia existentes, además la infraestructura disponible (mangueras, red seca y húmeda) no funcionó. El incendio ocasionó la muerte de 66 internos en el ala sur del cuarto piso de la torre 5, donde se inició la riña, y la de 15 internos del ala norte, quienes murieron como consecuencia de la inhalación de gases tóxicos, ya que no fueron oportunamente evacuados.

\section{Normativa internacional aplicable}

Recordando que las concepciones actuales entienden al derecho como un conjunto amplio de disposiciones que involucran tanto al ordenamiento jurídico interno como al internacional ${ }^{33}$, diversos instrumentos internacionales protegen los derechos vulnerados en el caso analizado, como el Pacto Internacional de Derechos Civiles y Políticos (PIDCP) ${ }^{34}$, la Convención Americana sobre Derechos Humanos $(\mathrm{CADH})^{35}$, las Reglas Mínimas para el Tratamiento de los Reclusos ${ }^{36}$, los Principios Básicos para el Tratamiento de los Reclusos ${ }^{37}$, el Conjunto de Principios para la Protección de todas las Personas Sometidas a cualquier forma de Detención o Prisión ${ }^{38}$, y los Principios y Buenas Prácticas sobre la Protección de las Personas Privadas de Libertad en las Américas (Principios y Buenas Prácticas) ${ }^{39}$.

31 Ley Orgánica de Gendarmería de Chile artículos 1, $3^{\circ}$ y 15; Reglamento de Establecimientos Penitenciarios artículos $1^{\circ}, 4^{\circ}, 6^{\circ}, 10$ y 25; Resolución 2854 de Organización Administrativa de los Establecimientos Penitenciarios artículos 23 y 41

32 CASTRO, Álvaro. Sistema Penitenciario y Derechos Humanos. Informe Anual de Derechos Humanos, (9): 109-145, 2011, p. 112.

33 GUZMÁN, José Luis. Crímenes internacionales y prescripción. En: AMBOS, Kai, MALARINO, Ezequiel y WOISCHNIK, Jan (Eds.). Dificultades jurídicas y políticas para la ratificación o implementación del Estatuto de Roma de la Corte Penal Internacional. Montevideo, Konrad-Adenauer-Stiftung, 2005, 171-196, p. 180.

34 Del año 1966, suscrito por Chile el 16 de septiembre de 1971, habiéndose depositado el instrumento de ratificación el 10 de febrero de 1972 y efectuada su promulgación por Decreto Supremo № 778, de 30 de noviembre de 1976. Su publicación en el D.O. se efectuó el 29 de abril de 1989.

35 Adoptada el 22 de noviembre de 1969, entrada en vigor el 16 de junio de 1978, su ratificación por Chile se produjo el 21 de agosto de 1990 y su publicación en el D.O. se efectuó el 5 de enero de 1991.

36 Adoptadas por el Primer Congreso de las Naciones Unidas sobre Prevención del Delito y Tratamiento del Delincuente, celebrado en Ginebra en 1955, y aprobadas por el Consejo Económico y Social en sus resoluciones 663C (XXIV) de 31 de julio de 1957 y 2076 (LXII) de 13 de mayo de 1977.

37 Adoptados y proclamados por la Asamblea General de las Naciones Unidas en su resolución 45/111, de 14 de diciembre de 1990.

38 Adoptado por la Asamblea General de las Naciones Unidas en su resolución 43/173, de 9 de diciembre de 1988

39 Adoptados por la Comisión Interamericana de Derechos Humanos en su resolución 1/08, 13 de marzo 2008. 
Si bien algunas de estas normas son etiquetadas como soft law ${ }^{40}$, conviene destacar que tanto el PIDCP como la CADH, son tratados internacionales sobre derechos fundamentales que de conformidad a la Constitución chilena ${ }^{41}$ gozan de jerarquía constitucional, y en ese carácter deben ser observados y aplicados por los tribunales nacionales, como también, forman parte del corpus iuris interamericano ${ }^{42}$. Adicionalmente, parece particularmente relevante mencionar que una de las disposiciones reglamentarias vulneradas por los acusados, establece expresamente la obligación de actuar en conformidad "con las garantías y dentro de los límites establecidos por la Constitución Política de la República, [y] los tratados internacionales ratificados por Chile" ${ }^{\prime 3}$.

Específicamente, nos enfocaremos en las obligaciones que surgen de la CADH que en su artículo primero establece dos importantes obligaciones para los Estados partes: respetar los derechos humanos, y garantizar su ejercicio y goce de todas las personas sujetas a su jurisdicción. La obligación de respetar exige que ni el Estado, ni sus agentes, ni terceros, violen los derechos humanos establecidos en la Convención ${ }^{44}$. Mientras que la obligación de garantizar exige al Estado emprender las acciones necesarias para asegurar que todas las personas sujetas a su jurisdicción estén en condiciones de ejercerlos y gozarlos. Estas obligaciones son de inmediata exigibilidad para "todo el aparato gubernamental y, en general, para todas las estructuras a través de las cuales se manifiesta el ejercicio del poder público" ${ }^{45}$, desde el momento en que la Convención entró en vigor.

Nos referiremos al incumplimiento de tales obligaciones por el Estado de Chile, en primer lugar como garante de los derechos de las personas que están bajo su jurisdicción y especialmente de quienes se encuentran privados de libertad, referida al deber de cuidado que debería haber caracterizado el accionar de Gendarmería al interior del penal de San Miguel, antes y durante el incendio. En segundo lugar, al deber estatal de investigar y sancionar a los responsables de toda grave vulneración a los derechos fundamentales.

\subsection{Políticas penitenciarias}

Las condiciones de la Cárcel de San Miguel eran conocidas por la autoridad. Sin embargo, la respuesta frente a ellas fue nula. Las autoridades no adoptaron modificaciones presupuestarias para mejorar las condiciones generales de las prisiones. En concreto, no se disminuyó la cantidad de internos del penal, no se elaboraron planes de seguridad, ni se generaron cambios normativos de ningún tipo, infringiendo así su obligación respecto de las personas privadas de libertad, con fundamento en los artículos 5 de la CADH y 10 del PIDCP, en relación con la obligación general de adoptar todas las medidas necesarias para velar por la salvaguarda de los derechos humanos contenidos en las mencionadas disposiciones.

40 El término soft law se utiliza para referirse aquellos acuerdos internacionales suscritos entre los Estados y los organismos internacionales, con el objeto de contraer compromisos sin concluir un tratado formal en virtud del derecho internacional.

41 Artículo $5^{\circ}$, inciso $2^{\circ}$ de la Constitución Política de la República

42 De acuerdo a esta doctrina sentada por la Corte IDH: "El corpus juris del Derecho Internacional de los Derechos Humanos está formado por un conjunto de instrumentos internacionales de contenido y efectos jurídicos variados (tratados, convenios, resoluciones y declaraciones)". Así: Corte IDH. El derecho a la información sobre la asistencia consultar en el marco de las garantías del debido proceso legal. Opinión Consultiva OC-16/1999, de 1 de octubre de 1991, párr. 115.

43 Reglamento de Establecimientos Penitenciarios, Artículo 4.

44 MEDINA, Cecilia y NASH, Claudio. Sistema Interamericano de Derechos Humanos. Introducción a sus Mecanismos de Protección. Santiago, Centro de Derechos Humanos, Facultad de Derecho, Universidad de Chile, 2007 , p. 19.

45 Corte IDH. Caso Garibaldi vs. Brasil. Excepciones Preliminares, Fondo, Reparaciones y Costas. Sentencia de 23 de septiembre de 2009. Serie C No. 203, párr. 111. 
En lo concerniente a políticas públicas sobre el sistema penitenciario, la Corte Interamericana de Derechos Humanos (Corte IDH) indica que del artículo 5 de la Convención, en relación con los artículos 1.1 y 2, se desprende el deber del Estado de "diseñar y aplicar una política penitenciaria de prevención de situaciones críticas que pondría en peligro los derechos fundamentales de los internos en custodia" ${ }^{46}$.

En el mismo sentido, la $\mathrm{CIDH}$ ha indicado en reiteradas oportunidades que la obligación del Estado de proteger la vida de las personas bajo su custodia, conlleva la mitigación de situaciones de riesgo, por lo que debe asegurarse de contar con mecanismos de prevención de emergencias. ${ }^{47}$ Además, sostiene que el Estado debe capacitar al personal en protocolos de evacuación, asistencia y "reacción frente a este tipo de eventos"48.

\subsection{Condiciones carcelarias}

El artículo 4.1 de la CADH reconoce el derecho a la vida. De ello se deriva la obligación de los Estados de abstenerse de toda privación arbitraria de ella, existiendo además la obligación de protección respecto de personas bajo su custodia. La Corte IDH ha establecido que "[f]rente a las personas privadas de libertad, el Estado se encuentra en posición especial de garante, toda vez que las autoridades penitenciarias ejercen un fuerte control o dominio sobre las personas que se encuentran sujetas a su custodia" ${ }^{\prime 9}$. La posición especial de garante del Estado también se encuentra reconocida en el Principio I de los Principios y Buenas Prácticas.

Según la Corte, dicha obligación requiere que el Estado "incorpore en el diseño, estructura, construcción, mejoras, manutención y operación de los centros de detención, todos los mecanismos materiales que reduzcan al mínimo el riesgo de que se produzcan situaciones de emergencia o incendios y en el evento que se produzcan estas situaciones se pueda reaccionar con la debida diligencia, garantizando la protección de los internos o una evacuación segura de los locales" ${ }^{50}$.

En el mismo sentido, el Principio XI de los Principios y Buenas Prácticas establece el derecho de las personas privadas de libertad a recibir una alimentación que corresponda en cantidad, calidad y condiciones de higiene. Las Reglas Mínimas para el Tratamiento de Reclusos establecen como regla general que "[...] todo recluso recibirá de la administración, a las horas acostumbradas, una alimentación de buena calidad, bien preparada y servida, cuyo valor nutritivo sea suficiente para el mantenimiento de su salud y de sus fuerzas" ${ }^{\prime \prime}$.

\subsection{Planes de seguridad y medidas de custodia}

De la condición especial de garante del Estado también se desprende que el personal a cargo de velar por la seguridad y orden dentro de las prisiones debe contar con capacitación con el fin

46 Corte IDH. Caso "Instituto de Reeducación del Menor" vs. Paraguay. Excepciones Preliminares, Fondo, Reparaciones y Costas. Sentencia de 2 de septiembre de 2004. Serie C No. 112, párr. 158; Corte IDH. Caso Pacheco Teruel y otros vs. Honduras. Fondo, Reparaciones y Costas. Sentencia de 27 de abril de 2012 Serie C No. 241, párr. 68.

$47 \mathrm{CIDH}$, Informe de Fondo No. 118/10, Caso 12.680, Rafael Arturo Pacheco Teruel y otros, 22 de octubre de 2010 (expediente de fondo, tomo I, folios 7 a 51), párr. 63.

48 Ibídem.

49 Corte IDH. Caso Bulacio vs. Argentina. Fondo, Reparaciones y Costas. Sentencia de 18 de septiembre de 2003. Serie C No. 100, párrs. 126 y 138.

50 Corte IDH. Caso Pacheco Teruel y otros vs. Honduras, op. cit.

51 Regla 20, Reglas Mínimas para el Tratamiento de Reclusos. 
de realizar un buen desempeño de sus funciones. Por ejemplo, el Principio XX de los Principios y Buenas Prácticas establece que el personal a cargo de los centros de detención debe recibir instrucción inicial y periódica. Dicha instrucción debe incluir, como mínimo, capacitación en materia de derechos humanos, derechos y deberes específicos de sus funciones; además de los principios sobre el uso de la fuerza, armas de fuego, y de contención física.

El Principio XX de las Reglas Mínimas para el Tratamiento de Reclusos contiene los requisitos y directrices que debe observar "[e]l personal que tenga bajo su responsabilidad la dirección, custodia, tratamiento, traslado, disciplina y vigilancia de personas privadas de libertad". Además establece que este deberá ser "calificado y suficiente para garantizar la seguridad, vigilancia, custodia, y para atender las necesidades médicas, psicológicas, educativas, laborales y de otra índole".

En este sentido, conviene recordar que la Corte Europea en el Caso Paul and Audrey Edwards v. UK, sostuvo "las personas detenidas se encuentran en una situación vulnerable y que las autoridades tienen la obligación de protegerlas. Siendo responsabilidad del Estado dar cuenta de las lesiones que las personas privadas de libertad sufran durante la custodia, obligación que es particularmente rigurosa cuando los individuos mueren" ${ }^{52}$. Mientras que en el Caso Rodić and 3 Others v. Bosnia And Herzegovina indicó que el Estado incumplió con su obligación de garante de la vida de los detenidos al "fallar en protegerlos de las persecuciones de sus compañeros" ${ }^{53}$.

Por su parte, la $\mathrm{CIDH}$ ha declarado que los incendios en cárceles, independientemente de que hayan sido causados por un brote de violencia, se producen en contextos de incumplimiento de los estándares internacionales, en condiciones de riesgos conocidas por las autoridades ${ }^{54}$. Esta situación genera la subsecuente responsabilidad internacional del Estado por la vulneración de los derechos humanos de que fueron víctimas personas privadas de libertad y bajo su custodia.

En el caso de San Miguel se produjo en una cárcel sobrepoblada, con infraestructura deteriorada, y en circunstancias en las que las autoridades fueron manifiestamente negligentes en controlar la emergencia. Su bajo nivel de profesionalización se evidenció en el incumplimiento de la normativa administrativa, en la omisión de llevar a cabo las rondas de vigilancia, en la prevención del incendio finalmente, al no responder conforme al protocolo de evacuación en situaciones de emergencia.

\subsection{Obligación de sancionar}

Los Estados partes de la Convención Americana tienen la obligación de investigar y sancionar las graves violaciones a los derechos humanos. El artículo 25 de la Convención establece la obligación del Estado de proveer a las personas dentro de su jurisdicción la debida protección judicial ${ }^{55}$. La jurisprudencia supranacional ha desarrollado este concepto señalando que tal protección se manifiesta en el derecho que tiene toda persona a que los tribunales competentes sustancien sus procesos en concordancia con las reglas del debido proceso (art. 8.1 CADH) ${ }^{56}$. Este derecho

\footnotetext{
52 European Court of Human Rights (ECHR) [Third Section]. Paul and Audrey Edwards v. the United Kingdom. Application No. 46477/99, 14 March 2002, §54-56

53 ECHR [Fourth Section]. Rodić and Others v. Bosnia and Herzegovina. Application No. 22893/05, 27 May $2008 . \S 51$.

$54 \mathrm{CIDH}$, Informe sobre los derechos humanos de las personas privadas de libertad en las Américas, op. cit., p. 114.

55 CIDH. Informe No 35/96, caso 10.832, Luis Lizardo Cabrera, República Dominicana, 19 de febrero de 1998. Corte IDH. Garantías Judiciales En Estados de Emergencia (artículos 27.2, 25 y 8 Convención Americana Sobre Derechos Humanos) Opinión Consultiva OC 9/87, del 6 de octubre de 1987, párr. 23.

56 Ibídem.
} 
no se agota con el libre acceso a un recurso y su desarrollo, sino que requiere que el órgano interviniente produzca una conclusión razonada sobre los méritos del reclamo formulado por las víctimas ${ }^{57}$. Este es el llamado derecho a la tutela judicial efectiva (Arts. 1.1, 8.1, 25, CADH), que comprende, entre otros, el derecho de la víctima a obtener una sentencia o resolución motivada.

La impunidad resultante de las decisiones del Poder Judicial chileno en este caso se opone a lo afirmado por la CIDH, que ha subrayado que los Estados tienen la obligación de conducir investigaciones serias, diligentes e imparciales de los incendios que se produzcan en los centros de privación de libertad, que conduzcan a la sanción penal y administrativa de todas aquellas autoridades que tuvieron algún grado de responsabilidad, garantizando además a una efectiva reparación de las víctimas ${ }^{58}$. En este caso el Tribunal ambiguamente reconoció la existencia de responsables de la siguiente manera:

"[E]ste Tribunal, ha llegado a la plena convicción de que la tragedia acaecida el 08 de Diciembre (sic) de 2010 al interior de la cruceta 5, piso 4, del CDP San Miguel tiene responsables, pero que de modo alguno corresponden a quienes al día de hoy ostentan la calidad procesal de acusados en el caso sub lite ${ }^{\prime \prime 59}$.

Previniendo el Magistrado Huberman su interés de incluir luego de la palabra "responsables" la frase "al menos uno constantemente citado y criticado en este juicio, esto es, el Estado de Chile"60.

La CIDH ha fijado un estándar alto en relación con el deber estatal de investigar y sancionar situaciones acaecidas en recintos penitenciarios, precisamente porque es el Estado "el que cuenta con el control de todos los medios probatorios para aclarar los hechos" ${ }^{\prime 61}$. Por su parte la Corte IDH ha enfatizado que el incumplimiento de tales obligaciones implica una desprotección efectiva de los derechos contenidos en la Convención, insistiendo que cualquier forma de "impunidad propicia la repetición crónica de las violaciones de derechos humanos y la total indefensión de las víctimas y de sus familiares" ${ }^{\prime \prime 2}$.

Por su parte, desde el Caso McCann and Others v. UK 63 , el sistema europeo de derechos humanos ha indicado que los Estados deben llevar a cabo investigaciones oficiales efectivas cuando individuos han muerto como resultado de acciones $u$ omisiones estatales ${ }^{64}$. A juicio de la Corte Europea las investigaciones son un componente indispensable para la protección de la vida en las jurisdicciones nacionales ${ }^{65}$, que garantizan la adecuada rendición de cuentas del Estado ${ }^{66}$ y evitan la impunidad de los responsables. La investigación debe adecuarse a las características y dificultades del crimen para cumplir con su objetivo de identificación y sanción de los responsables ${ }^{67}$.

$57 \mathrm{CIDH}$, Informe № 2/97, casos 11.205, 11.236 y otros, Argentina, del 30 de agosto de 1997.

$58 \mathrm{CIDH}$, Informe sobre los derechos humanos de las personas privadas de libertad en las Américas, op. cit., p. 115.

59 Sexto TJOP. Acta de deliberación Juicio Oral. Acta de 30 de abril de 2014. Causa RUC № 1.001.141.178-4. Considerando 13. El destacado es del original.

60 Ibídem. La cursiva es del original.

61 Ibídem, p. 136.

62 Corte IDH. Caso Juan Humberto Sánchez vs. Honduras. Interpretación de la Sentencia de Excepciones Preliminares, Fondo y Reparaciones. Sentencia de 26 de noviembre de 2003. Serie C No. 102, párrs. 143 y 185.

63 ECHR [Grand Chamber]. McCann and Others v. UK. Application No. 324, 27 September 1995.

64 ECHR [Grand Chamber]. Salman v. Turkey. Application No. 21986/93, 27 June 2000, § 104.

65 ECHR. Hugh Jordan v. the United Kingdom. Application No. 24746/94, 4 May 2001, § 128.

66 ECHR. Kaya v. Turkey. 19 February 1998, Reports of Judgments and Decisions 1998-I.

67 ECHR [Grand Chamber]. Al-Skeini and Others v. the United Kingdom. Application No. 55721/07, 7 July $2011, \S 72$. 


\section{Conclusión}

Los hechos objeto del presente análisis constituyen graves vulneraciones a los derechos humanos, en expresa vulneración a los artículos 4.1, 5 párrafos 1 y 2, y 4 en relación con los artículos 1.1 y 2 de la CADH. El incendio cobró la vida de 81 personas debido a las omisiones de las autoridades responsables de mejorar las condiciones del penal, tanto en lo que respecta a la infraestructura física, como en lo que respecta al capital humano y la elaboración de los planes de emergencia. Los custodios no velaron por la seguridad y vida de los reos, no previeron la violencia interna, ni respondieron adecuadamente a la emergencia. Deficiencias que crearon la situación de alto riesgo que culminó con la muerte de 81 de los internos.

Además de la falta en la adopción de medidas de carácter administrativo para salvaguardar la seguridad de las personas bajo su custodia, el Estado, a través de la judicatura, falló en proveer un recurso judicial efectivo para las víctimas. El Sexto Tribunal Oral en lo Penal omitió considerar y ponderar las normas de derechos humanos de rango constitucional, originando una vulneración a los artículos 8.1 y 25.1 en relación con el artículo 1.1 de la Convención, en perjuicio de las víctimas del incendio y sus familiares.

Conforme lo sostenido por la Corte Interamericana desde el Caso Velásquez Rodríguez, todos los actores que participan del sistema judicial, pero particularmente quienes administran justicia, tienen la obligación de "prevenir, investigar y sancionar toda violación de los derechos reconocidos por la Convención y procurar, además, el restablecimiento, si es posible, del derecho conculcado y, en su caso, la reparación de los daños producidos por la violación de los derechos humanos" ${ }^{68}$. Esta obligación, a nuestro juicio, no fue observada por el veredicto absolutorio del Sexto Tribunal del Juicio Oral en lo Penal, ni por la Corte de Apelaciones de San Miguel.

68 Corte IDH. Caso Velásquez Rodríguez vs. Honduras. Excepciones Preliminares. Sentencia de 26 de junio de 1987. Serie C No. 1, párr. 174 